УДК 33.331 JEL J01

Симутова Дарья Викторовна аспирант, ФГОБУ ВО «Финансовый университет при Правительстве Российской Федерации», г. Москва e-mail: simutova.d@mail.ru

\section{Simutova Darya}

Postgraduate student, Financial University under the Government of the Russian Federation, Moscow e-mail: simutova.d@mail.ru

\section{СУЩНОСТЬ ПРОБЛЕМ УПРАВЛЕНИЯ ЭФФЕКТИВНОСТЬЮ ПРОФЕССИОНАЛЬНОЙ СЛУЖЕБНОЙ ДЕЯТЕЛЬНОСТИ ГОСУДАРСТВЕННЫХ СЛУЖАЩИХ НА ЭТАПЕ ПРИВЛЕЧЕНИЯ И ОТБОРА}

\begin{abstract}
Аннотация. Исследованы проблемы управления эффективностью профессиональной служебной деятельности государственных гражданских служащих, выраженные в недостаточном профессионализме и компетентности служащих. Проблемы, возникающие на этапе привлечения персонала на государственную гражданскую службу Российской Федерации, рассмотрены с точки зрения установленных квалификационных требований к должностям государственных служащих. Причина проблем на этапе отбора раскрыта в практике использования методик оценки кандидатов на замещение должностей государственной гражданской службы.
\end{abstract}

Ключевые слова: государственные гражданские служащие, профессиональная служебная деятельность, управление эффективностью, профессионализм, компетентность.

\section{ESSENCE OF THE PROBLEMS OF PERFORMANCE MANAGEMENT OF PROFESSIONAL SERVICE ACTIVITIES OF CIVIL SERVANTS AT THE STAGE OF RECRUITMENT AND SELECTION}

\begin{abstract}
The problems of managing the effectiveness of professional service activities of civil servants, expressed in the lack of professionalism and competence of employees, have been investigated. The problems that arise at the stage of attracting personnel to the civil service of the Russian Federation have been considered from the point of view of the established qualification requirements for civil service positions. The cause of the problems at the selection stage has been disclosed in the practice of using methods for evaluating candidates for positions in the civil service.
\end{abstract}

Keywords: public civil servants, professional service activities, performance management, professionalism, competence.

Одним из главных приоритетов государственного управления кадрами является внедрение эффективных механизмов обеспечения государственной гражданской службы высококвалифицированными специалистами, готовыми к решению сложных задач государственного менеджмента.

Недостаточность компетентности и профессионализма государственных служащих подтверждается исследованиями, авторы которых приходят к выводам не только о нехватке знаний, профессиональных навыков и компетентности гражданских служащих, но и о несоответствии их профессиональных качеств конкретной должности государственной службы $[7 ; 8 ; 10]$.

В результате недостаток необходимых знаний, навыков и опыта госслужащих оказывает негативное влияние на качество и эффективность их служебной деятельности.

Так, поиск подходов к управлению эффективностью профессиональной служебной деятельности государственных гражданских служащих следует осуществлять, исходя из существующих проблем недостаточного профессионализма и компетентности личного состава государственного органа. Не случайно Федеральным законом от 27 июля 2004 г. № 79-Ф3 «О государственной гражданской службе Российской Федерации» закреплен принцип профессионализма и компетентности государственных служащих [1].

Основные понятия и категории эффективности профессиональной служебной деятельности госслужащих . Понятие «профессиональная деятельность», чаще всего, определяется как деятельность человека в рамках какой-либо профессии или по определенной специальности. Тогда как категория «профессионализм»

( С Симутова Д.В., 2019. Статья доступна по лицензии Creative Commons «Attribution» («Атрибуция») 4.0. всемирная (http://creativecommons.org/licenses/by/4.0/).

The Author(s), 2018. This is an open access article under the CC BY 4.0 license (http://creativecommons.org/licenses/by/4.0/).

(c) (i) 
характеризуется как особенность личности, требующая совокупности специальных знаний, умений навыков, опыта, развивающаяся в процессе трудовой деятельности, проявляющаяся исключительно в профессиональной сфере и выражаемая высокими достижениями и результатами труда носителя.

Для формулирования более точного определения категории «профессионализм» необходимо рассмотреть соотношение данного термина с такими смежными понятиями, как квалификация, компетенция, компетентность, мастерство.

О. Л. Чуланова предлагает следующее определение: «Компетенция - это социально-трудовая характеристика совокупности знаний, умений, навыков, профессиональных качеств и мотивационных характеристик работника, обладающих эмерджентностью, необходимых для успешного выполнения работы и соответствующих требованиям должности и стратегическим целям организации» $[11$, с. 39]. Это определение достаточно полно отражает понятие «компетенция», учитывая не только сферу знаний и опыта работника, оно также отражает мотивационный аспект, имеет отсылку к успешному результату. При этом автор делает особый акцент на том, что компетенцией можно считать не все характеристики работника, а лишь актуальные для конкретной ситуации или организации. «Компетентность - понятие более широкое. Оно предполагает наличие у человека некоторой совокупности развитых до необходимого уровня компетенций» [11, с. 42]. Компетентность здесь представляет собой совокупность ранее упомянутых актуальных компетенций, а их развитие до определенного уровня невозможно без достаточного опыта их практического применения.

Согласно Н.Ф. Алтуховой с соавторами, «компетентность - способность проявления совокупности компетенций в профессиональной деятельности» [7]. Это определение дополняет первое, однако также не учитывает степень успешности профессиональной деятельности.

Такая способность подразумевает наличие стандартов профессионального поведения. «Стандарты профессионального поведения - словесное описание ожидаемых проявлений профессиональных качеств в поведении гражданского служащего» [9]. Словесное описание ожидаемых проявлений профессиональных качеств госслужащих формируют модель ожидаемого поведения.

Таким образом, переход от квалификации к компетенции предполагает наличие у работника четкого представления о модели ожидаемого от него поведения, о структуре процесса выполнения порученного задания, о качественных и количественных характеристиках ожидаемых результатов и эффективных способах их достижения (рис. 1).

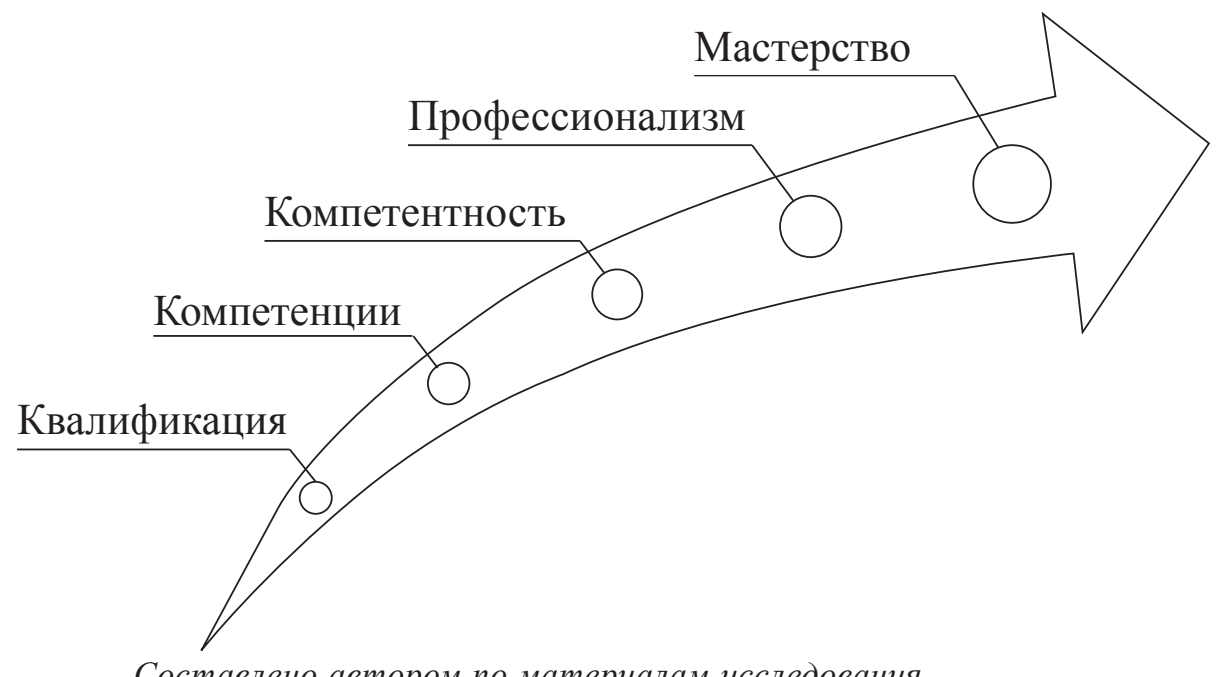

Составлено автором по материалам исследования

Рис. 1. Этапы профессионального развития

Сущность проблем профессионализма и компетентности государственных служащих на этапе привлечения на гражданскую службу. Уровень компетентности требует от госслужащего опыт однократного (и более) самостоятельного успешного достижения результата при выполнении возложенной на него функции или порученного задания при прочих равных условиях и ресурсах, а также проявления при этом работником необходимой для выполнения данных функций и заданий совокупности компетенций. Кроме того, на этом 
этапе немаловажное значение приобретает мотивационный аспект. Профессионализм предполагает многократный опыт самостоятельного успешного достижения результата при выполнении всего спектра возложенных на специалиста функций и задач, в том числе (при наличии высокой мотивации) в условиях ограниченных ресурсов. Мастерство характеризуется высоким уровнем профессионализма, высоким уровнем качества и эффективности трудовой деятельности в совокупности с самомотивацией, направленной, как правило, на успешный творческий поиск новых подходов и методов к решению задач. Наконец, эффективность профессиональной деятельности служащего в результате будет напрямую зависеть от успешного перехода на последующий этап профессионального развития. А в дальнейшем - от возможности сохранить достигнутый уровень, добавить к нему новые качественные элементы, которые и составляют профессиональное развитие кадрового состава государственного органа. Таким образом, нами дано определение «профессиональной деятельности», под которой будет пониматься целенаправленная деятельность личности, обладающей как совокупностью специальных знаний, умений, навыков и опыта, так и развитой способностью применять их на практике, умением и мотивацией развивать эти качества в процессе трудовой деятельности и достигать высоких результатов.

Профессиональная деятельность как непрерывный процесс обусловливает рассмотрение сущности обозначенных проблем на основных этапах профессиональной служебной деятельности государственных гражданских служащих.

В соответствии с Федеральным законом от 27 июля 2004 г. № 79-Ф3 «О государственной гражданской службе Российской Федерации» объем полномочий по конкретной должности является одним из признаков гражданской службы. Так, для определения полномочий используется деление должностей государственной службы на категории и группы [1, ст. 9].

В зависимости от категорий и групп должностей гражданской службы для их замещения к госслужащим устанавливаются квалификационные требования, а также порядок назначения на должность, присвоения классных чинов. При этом квалификационные требования к госслужащим ограничиваются установлением уровня профессионального образования и стажа государственной службы.

П. А. Меркулов отмечает, что на государственной службе формы и характер профессионального образования, соответствующие профилю профессиональной деятельности определены только в общем виде. Также автор отмечает отсутствие процессов, связывающих профессиональное развитие с продвижением государственных гражданских служащих по должности. Решение этой проблемы он видит в разработке методологии профессионализации государственной гражданской службы - формирование соотнесения функционала должностей государственной гражданской службы и направления (специальности), по которой получено образование. «Это должно стать фундаментом профессионального развития и профессионализации кадровой политики» - считает автор [8, с. 112]. Оценивая данное определение, стоит согласиться, что теоретические знания, которые дает профильное образование, действительно составляют необходимую базу для вхождения в профессиональную среду. Дальнейшую же надстройку составляют практические компетенции, формирующиеся в результате практического опыта. При этом для реализации соотнесения функционала должностей госслужбы и направления полученного образования, о котором говорит автор [8] необходимо долгосрочное узкоспециализированное развитие каждого конкретного потенциального госслужащего, включающее как получение образования, так и дальнейшую служебную деятельность определенной направленности, стимулирование дальнейшего роста и развития в этом направлении. В сегодняшних условиях данный сценарий реализовать практически невозможно.

Таким образом, одной из проблем профессионализма и компетентности госслужащих является то, что профессиональное образование государственных гражданских служащих недостаточно ориентировано на профессиональные потребности государственного органа. Но с точки зрения качественного управления эффективностью профессиональной служебной деятельности государственных гражданских служащих профильного образования недостаточно. Для решения проблем недостаточного профессионализма и компетентности необходима методическая работа кадровых служб государственных органов в области управления практическими компетенциями: накопление и передача опыта.

16 января 2017 г. Президент Российской Федерации (далее - РФ) подписал Указ № 16 «О квалификационных требованиях к стажу государственной гражданской службы или стажу работы по специальности, направлению подготовки, который необходим для замещения должностей федеральной государственной гражданской службы», значительно снизив требования к стажу, необходимому для замещения должностей 
государственной гражданской службы [3]. В рамках государственного управления данное решение положительно - это необходимая мера для восполнения кадров высшей группы должностей федеральной государственной гражданской службы. Однако указ № 16 стал стимулом к снижению профессионально-квалификационного уровня вновь принятых на гражданскую службу, что является негативным фактором с точки зрения эффективности профессиональной деятельности госслужащих. Новый указ Президента РФ приравнял стаж работы по специальности к опыту на госслужбе и снизил требования к стажу, необходимому для замещения той или иной должности гражданской службы. Актуальные требования к кандидатам представлены в таблице 1.

Таблииа 1

Квалификационные требования к должностям государственной гражданской службы на примере федерального органа исполнительной власти Российской Федерации

\begin{tabular}{|c|c|c|c|c|}
\hline $\begin{array}{c}\text { Уровень об- } \\
\text { разования }\end{array}$ & Категории & Наименование должности & Группа & Квалификационные требования \\
\hline \multirow{3}{*}{ 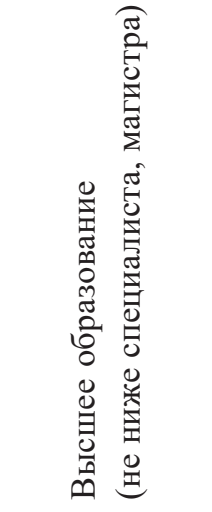 } & Руководители & $\begin{array}{l}\text { Заместитель министра } \\
\text { Директор департамента } \\
\text { Заместитель директора депар- } \\
\text { тамента }\end{array}$ & \multirow[t]{2}{*}{ 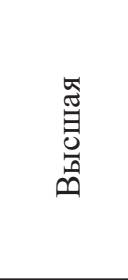 } & \multirow{2}{*}{$\begin{array}{l}\text { Не менее } 4 \text { лет стажа государствен- } \\
\text { ной гражданской службы или стажа } \\
\text { работы по специальности, направле- } \\
\text { нию подготовки }\end{array}$} \\
\hline & $\begin{array}{l}\text { Помощники } \\
\text { (советники) }\end{array}$ & $\begin{array}{l}\text { Помощник министра } \\
\text { Советник министра }\end{array}$ & & \\
\hline & \multirow[t]{2}{*}{ Специалисты } & \multirow{2}{*}{$\begin{array}{l}\text { Начальник отдела } \\
\text { Референт } \\
\text { Заместитель начальника отдела } \\
\text { Ведущий советник } \\
\text { Советник } \\
\text { Ведущий консультант } \\
\text { Консультант }\end{array}$} & 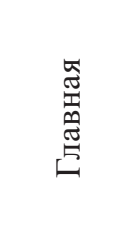 & $\begin{array}{l}\text { Не менее } 2 \text { лет стажа государственной } \\
\text { гражданской службы или стажа работы } \\
\text { по специальности, направлению под- } \\
\text { готовки (для имеющих диплом «с от- } \\
\text { личием» не менее одного года) }\end{array}$ \\
\hline \multirow{3}{*}{ 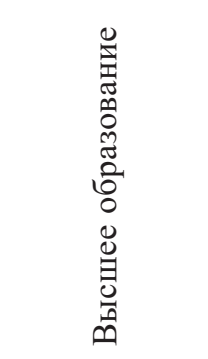 } & & & \multirow{2}{*}{ 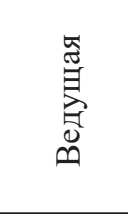 } & \multirow{5}{*}{ Требований к стажу нет } \\
\hline & $\begin{array}{l}\text { Обеспечива- } \\
\text { ющие специа- } \\
\text { листы }\end{array}$ & Ведущий специалист 2 разряда & & \\
\hline & Специалисты & $\begin{array}{l}\text { Главный специалист-эксперт } \\
\text { Ведущий специалист-эксперт } \\
\text { Специалист-эксперт }\end{array}$ & \multirow{2}{*}{ U } & \\
\hline \multirow[b]{2}{*}{ 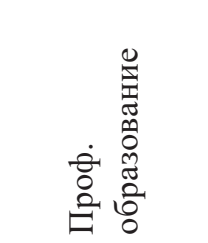 } & \multirow[b]{2}{*}{$\begin{array}{l}\text { Обеспечива- } \\
\text { ющие специа- } \\
\text { листы }\end{array}$} & \multirow{2}{*}{$\begin{array}{l}\text { Старший специалист } 1 \text { разряда } \\
\text { Старший специалист } 2 \text { разряда } \\
\text { Старший специалист } 3 \text { разряда } \\
\text { Специалист } 1 \text { разряда } \\
\text { Специалист } 2 \text { разряда }\end{array}$} & & \\
\hline & & & 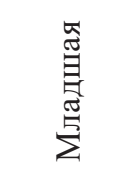 & \\
\hline
\end{tabular}

Составлено автором по материалам исследования

Для главной и высшей группы должностей необходим уровень образования не ниже специалиста или магистра. При этом для высшей группы должностей установлен минимальный уровень стажа госслужбы или стажа работы по специальности - четыре года. Стоит отметить, что для категории «руководители» такое требование является необоснованно низким. Для замещения должностей главной группы требуется не менее 2 лет стажа госслужбы или стажа работы по специальности и для имеющих диплом с отличием не менее года. Такие заниженные требования также не отвечают современным потребностям государственного органа в профессиональных и компетентных служащих. Для обеспечивающих специалистов младшей и старшей группы должностей достаточно среднего профессионального образования. Требования к таким специалистам обоснованы большим объемом в государственном органе несодержательных работ, 
не требующих высокой квалификации, а также сложностью привлечения на такие должности специалистов с высшим образованием. Как следует из таблицы 1, фактически с 16 января 2017 г. специалистам, претендующим на должность государственной гражданской службы до уровня должности «Заместитель начальника отдела» включительно, достаточно иметь высшее образование, при этом требований к стажу официально не предъявляют, что зачастую приводит к проблемам недостаточного профессионализма и компетентности вновь принятых работников.

Сущность проблем профессионализма и компетентности государственных служащих на этапе отбора. Помимо соответствия квалификационным требованиям, кандидатам на замещение должностей государственной гражданской службы необходимо пройти отборочные процедуры. Так, поступление гражданина на гражданскую службу осуществляется по результатам конкурса $[1 ; 2]$. Процедура проведения конкурса на государственной гражданской службе призвана обеспечивать поступление на службу наиболее компетентных, квалифицированных и достойных кандидатов, объективность и прозрачность отбора. Одной из проблем является то, что на практике конкурс на замещение должностей или на включение в кадровый резерв данную функцию не выполняет, имеет формальный бюрократический характер.

Отбор кадров на государственную гражданскую службу регламентируется Положением о конкурсе на замещение вакантной должности государственной гражданской службы РФ, утвержденным Указом Президента РФ от 1 февраля 2005 г. № 112 «О конкурсе на замещение вакантной должности государственной гражданской службы Российской Федерации», а также Методическим инструментарием по планированию найма и организации отбора кадров для замещения должностей государственной гражданской службы [2; 6]. Кроме того, для повышения объективности конкурсных процедур 31 марта 2018 г. Правительство РФ приняло постановление № 397 «Об утверждении единой методики проведения конкурсов на замещение вакантных должностей государственной гражданской службы и включение в кадровый резерв государственных органов» (далее - Единая методика) [4].

Единая методика определяет порядок подготовки и проведения конкурсов, предварительного тестирования, методы оценки профессиональных и личностных качеств, рекомендуемые к применению при проведении конкурсов. Согласно постановлению Правительства РФ № 397, для оценки профессионального уровня кандидатов, их соответствия квалификационным требованиям в ходе конкурсных процедур могут использоваться: индивидуальное собеседование, анкетирование, проведение групповых дискуссий, написание реферата и других письменных работ или тестирование по вопросам, связанным с выполнением должностных обязанностей по вакантной должности гражданской службы [4].

Предполагается, что применение Единой методики направлено на повышение объективности и прозрачности конкурсной процедуры и на формирование профессионального кадрового состава государственной гражданской службы. Единство подходов к конкурсным процедурам позволит исключить двоякое толкование методических рекомендаций, накопить знания и практический опыт работы с методикой, повысить эффективность ее использования и, как следствие, более эффективно управлять профессиональной служебной деятельностью государственных гражданских служащих. Однако проблемы конкурсных процедур остаются: Единая методика также не учитывает специфику работы каждого отдельного государственного органа и служащего в структурном подразделении, тематическое, информационное и качественное наполнение анкет, групповых дискуссий, или рефератов. Кроме того, федеральные органы исполнительной власти вправе принимать решение, исходя из собственных потребностей, интересов и ресурсов, в том числе о проведении или не проведении конкурса.

Конкурс на замещение должности гражданской службы не проводится:

1) в случае назначения на определенный срок, в том числе на должности категории «руководители» и «помощники» («советники») (при этом, служащим, назначенным на определенный срок, для присвоения классного чина необходимо пройти похожую процедуру - квалификационный экзамен);

2) при назначении на должности, на которые назначают Президент или Правительство РФ (не входит в компетенцию федерального органа исполнительной власти);

3) при назначении гражданского служащего, включенного в кадровый резерв [2]. При зачислении в кадровый резерв также проводят конкурс или используют комплексную оценку государственного гражданского служащего. 
В соответствии с Указом Президента РФ от 1 февраля 2005 г. № 112 «О конкурсе на замещение вакантной должности государственной гражданской службы Российской Федерации», конкурс может не проводиться при назначении на должности, исполнение должностных обязанностей по которым связано с использованием сведений, составляющих государственную тайну [2]. Соответствующий перечень должностей утверждается нормативным актом государственного органа.

Таким образом, наличие нормативно-правового акта с перечнем должностей, исполнение обязанностей по которым связано с использованием сведений, составляющих государственную тайну освобождает государственный орган от трудоемкой процедуры проведения конкурса на включение в кадровый резерв или на замещение должности государственной гражданской службы. Фактически отбор кандидатов происходит после изучения резюме и прохождения кандидатом многоуровневого собеседования. Такая тенденция связана с проблемой субъективной оценки кандидатов на должности и проявления непрофессионализма представителями кадровой службы государственного органа или уполномоченного на подбор лица.

Согласно данным опроса, проведенного в 2018 г. в Министерстве экономического развития (далее - Минэкономразвития) России, из двухсот опрошенных служащих, принятых в Минэкономразвития России в 2018 г., только трое поступили на государственную гражданскую службу через процедуру прохождения конкурса, что составляет 1,5 \% от общего числа респондентов. Из остальных служащих 1,5 \% назначены из кадрового резерва, а большая часть - 97 \% служащих были приняты через оформление допуска к государственной тайне.

На рисунке 2 представлено соотношение принятых в соответствии с порядком поступления на государственную гражданскую службу в Минэкономразвития России в 2018 г.

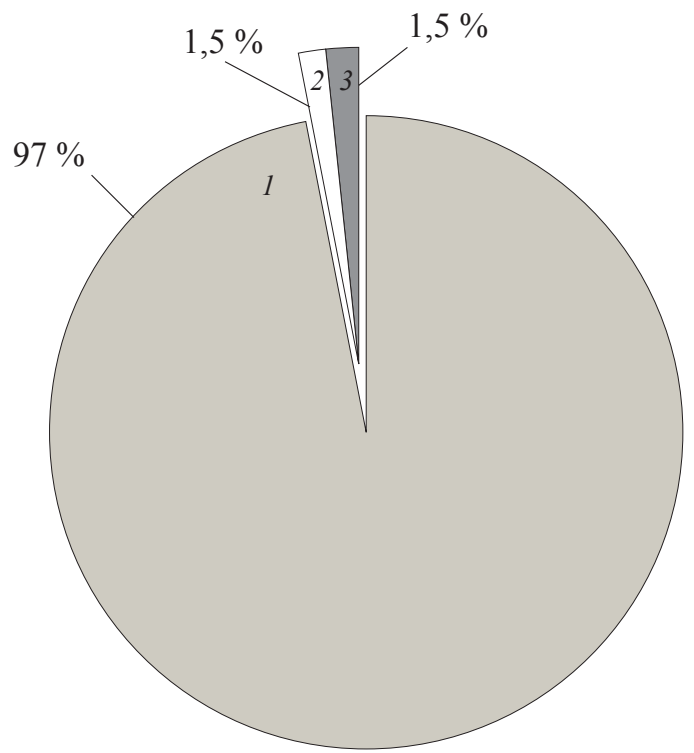

1 - через оформление допуска к государственной тайне; 2 - из кадрового резерва; 3 - выиграл конкурс

Составлено автором по материалам исследования

Рис. 2. Соотношение принятых в соответствии с порядком поступления на государственную гражданскую службу в Минэкономразвития России в 2018 г.

Представленные данные свидетельствуют о том, что только 3 \% вновь принятых сотрудников проходили конкурсную процедуру при отборе на должность. Таким образом, основной проблемой управления эффективностью профессиональной служебной деятельности госслужащих, выявленной на данном этапе, является уход от единых подходов к отбору, их субъективность и формализованность.

Итак, сущность проблем управления эффективностью профессиональной служебной деятельности госслужащих заключается в заниженных квалификационных требованиях к должностям государственной службы, которые не отвечают современным потребностям государственного органа в профессиональных и компетентных специалистах. Процедура отбора на государственную гражданскую службу через конкурс на замещение 
должностей, призванная обеспечить поступление на государственную службу наиболее профессиональных кандидатов и объективность оценки, носит формальный характер. Большая часть служащих назначается через оформление допуска к государственной тайне. Таким образом, сохраняется вероятность необъективной оценки возможностей кандидатов осуществлять профессиональную служебную деятельность.

Выявленные проблемы на этапе привлечения и отбора обусловливают необходимость дальнейшей работы в части уточнения и стандартизации требований к кандидатам, претендующим на замещение должностей государственной гражданской службы Российской Федерации, а также необходимость повышения объективности процедуры отбора и прозрачности при любом виде поступления на государственную гражданскую службу.

\section{Библиографический список}

1. Федеральный закон от 27.07.2004 г. № 79 «О государственной гражданской службе Российской Федерации» (ред. от 03.08.2018) [Электронный ресурс]. - Режим доступа: Справочная правовая система «КонсультантПлюс»: http://www. consultant.ru/cons (дата обращения: 25.12.2018).

2. Указ Президента Российской Федерации от 01.02.2005 г. № 112 «О конкурсе на замещение вакантной должности государственной гражданской службы Российской Федерации» (ред. от 10.09.2017) [Электронный ресурс]. - Режим доступа: Справочная правовая система «КонсультантПлюс»: http://www.consultant.ru/cons (дата обращения: 20.12.2018).

3. Указ Президента Российской Федерации от 16.01.2017 г. № 16 «О квалификационных требованиях к стажу государственной гражданской службы или стажу работы по специальности, направлению подготовки, который необходим для замещения должностей федеральной государственной гражданской службы» (ред. от 12.10. 2017) [Электронный ресурс]. - Режим доступа: Справочная правовая система «КонсультантПлюс»: http://www.consultant. ru/cons (дата обращения: 22.12.2018).

4. Постановление Правительства Российской Федерации от 31.03 .2018 г. № 397 «Об утверждении единой методики проведения конкурсов на замещение вакантных должностей государственной гражданской службы и включение в кадровый резерв государственных органов» [Электронный ресурс]. - Режим доступа: Справочная правовая система «КонсультантПлюс»: http://www.consultant.ru/cons (дата обращения: 22.12.2018).

5. Методический инструментарий по установлению квалификационных требований для замещения должностей государственной гражданской службы. Версия 3.2 (утв. Минтрудом России от 31.01.2018 г.) [Электронный ресурс]. - Режим доступа: Справочная правовая система «КонсультантПлюс»: http://www.consultant.ru/cons (дата обращения: 28.12.2018).

6. Методический инструментарий по планированию найма и организации отбора кадров для замещения должностей государственной гражданской службы. Версия 2.0 (утв. Минтрудом России от 31.07.2015 г.) [Электронный ресурс]. - Режим доступа: Справочная правовая система «КонсультантПлюс»: http://www.consultant.ru/cons (дата обращения: 28.12.2018).

7. Алтухова, Н. Ф. и др. Компетентностный подход в управлении кадрами государственной службы на основе онтологий / Н. Ф. Алтухова, Е. В. Васильева, М. В. Мирзоян // Бизнес-информатика. - 2018. - № 1(43). - С. 17-27.

8. Меркулов, П. А. Профессиональное развитие как элемент государственной политики повышения эффективности государственной гражданской службы // Вестник экспертного совета. - 2017. - № 1 (8). - С. 107-112.

9. Разработка эффективной системы мотивации трудовой деятельности госслужащих, ориентированной на достижение конечных результатов: отчет о НИР / Л. А. Жигун, А. О. Субочева, Н. С. Пряжников, А. А. Литвинюк, М. В. Полевая, Е. В. Камнева, М. Е. Смирнова, М. В. Рязанцева, С. А. Полевой, О. Н. Васильева, Р. А. Ширванов, Н. А. Крюкова, М. С. Ащеулова, К. Б. Джинджуа, Д. А. Зяблова. - М.: Финансовый университет при Правительстве Российской Федерации, 2017. - 187 с.

10. Чернышов, А. Г. Власть как «вечный» двигатель: Монография. - М.: Проспект, 2017. -240 с.

11. Чуланова, О. Л. Методология исследования компетенций персонала организаций: Монография. - М.: ИНФРА-М, 2015. $-120 \mathrm{c}$.

\section{References}

1. Federal'nyi zakon ot 27.07.2004 g. № 79 «O gosudarstvennoi grazhdanskoi sluzhbe Rossiiskoi Federatsii» (red. ot 03.08.2018 [Federal Law dated 27.07.2004 № 79 «On the State civil service of the Russian Federation» (ed. of 03.08.2018)]. Available at: Spravochnaya pravovaya sistema «Konsul'tantPlyus» http://www.consultant.ru/cons (accessed 25.12.2018).

2. Ukaz Prezidenta Rossiiskoi Federatsii ot 01.02.2005 g. № 112 «O konkurse na zameshchenie vakantnoi dolzhnosti gosudarstvennoi grazhdanskoi sluzhby Rossiiskoi Federatsii» (red. ot 1009.2017) [Decree of the President of the Russian Federation dated 01.02.2005 
№ 112 «On the competition for filling the vacant position of the civil service of the Russian Federation» (ed. of 10.09.2017)]. Available at: Spravochnaya pravovaya sistema «Konsul’tantPlyus» http://www.consultant.ru/cons (accessed 20.12.2018).

3. Ukaz Prezidenta Rossiiskoi Federatsii ot 16.01.2017 g. № 16 «O kvalifikatsionnykh trebovaniyakh k stazhu gosudarstvennoi grazhdanskoi sluzhby ili stazhu raboty po spetsial'nosti, napravleniyu podgotovki, kotoryi neobkhodim dlya zameshcheniya dolzhnostei federal'noi gosudarstvennoi grazhdanskoi sluzhby» (red. ot 12.10. 2017) [Decree of the President of the Russian Federation dated 16.01.2017 № 16 «On the qualification requirements for the length of service of the civil service or work experience in the specialty, the direction of training, which is necessary to fill the posts of the federal state civil service» (ed. of 12.10. 2017)]. Available at: Spravochnaya pravovaya sistema «Konsul'tantPlyus» http://www.consultant.ru/cons (accessed 22.12.2018).

4. Postanovlenie Pravitel’stva Rossiiskoi Federatsii ot 31.03.2018 g. № 397 «Ob utverzhdenii edinoi metodiki provedeniya konkursov na zameshchenie vakantnykh dolzhnostei gosudarstvennoi grazhdanskoi sluzhby i vklyuchenie v kadrovyi rezerv gosudarstvennykh organov» [Decree of the Government of the Russian Federation dated 31.03.2018 № 397 «On approval of a unified methodology for conducting tenders for the vacant positions of the civil service and inclusion in the personnel reserve of state bodies»]. Available at: Spravochnaya pravovaya sistema «Konsul’tantPlyus» http://www.consultant.ru/cons (accessed 22.12.2018).

5. Metodicheskii instrumentarii po ustanovleniyu kvalifikatsionnykh trebovanii dlya zameshcheniya dolzhnostei gosudarstvennoi grazhdanskoi sluzhby. Versiya 3.2: utv. Mintrudom Rossii ot 31.01.2018 g. [Methodological tools for establishing qualification requirements for the filling of civil service positions. Version 3.2 approved by Ministry of Labor of Russia 01.31.2018]. Available at: Spravochnaya pravovaya sistema «Konsul’tantPlyus» http://www.consultant.ru/cons (accessed 28.12.2018).

6. Metodicheskii instrumentarii po planirovaniyu naima i organizatsii otbora kadrov dlya zameshcheniya dolzhnostei gosudarstvennoi grazhdanskoi sluzhby. Versiya 2.0: utv. Mintrudom Rossii ot 31.07.2015 g. [Methodological tools for planning recruitment and selection of personnel for the posts of the civil service. Version 2.0 approved by Ministry of Labor of Russia 31.07.2015]. Available at: Spravochnaya pravovaya sistema «Konsul'tantPlyus» http://www.consultant.ru/cons (accessed 28.12.2018).

7. Altukhova N. F., Vasil'eva E. V., Mirzoyan M. V. Kompetentnostnyi podkhod v upravlenii kadrami gosudarstvennoi sluzhby na osnove ontologii [Competence-based approach in the management of civil service personnel on the basis of ontologies], Biznes-informatika, 2018, I. 1(43), pp. 17-27.

8. Merkulov P. A. Professional'noe razvitie kak element gosudarstvennoi politiki povysheniya effektivnosti gosudarstvennoi grazhdanskoi sluzhby. Vestnik ekspertnogo soveta [Professional development as an element of state policy to improve the efficiency of the civil service], Vestnik ehkspertnogo soveta, 2017, I. 1 (8), pp. 107-112.

9. ZhigunL. A. , Subocheva A. O., Pryazhnikov N. S., Litvinyuk A. A., Polevaya M. V., Kamneva E. V, Smirnova M. E., Ryazanceva M. V., Polevoi S. A., Vasil'eva O. N., Shirvanov R. A., Kryukova N. A., Ashcheulova M. S., Dzhindzhua K. B., Zyablova D. A. Razrabotka effektivnoi sistemy motivatsii trudovoi deyatel'nosti gossluzhashchikh, orientirovannoi na dostizhenie konechnykh rezul'tatov: otchet o NIR [Development of an effective system of motivation of civil servants'work oriented towards the achievement of final results: report on research and development], M.: Finansovyi universitet pri Pravitel'stve Rossiiskoi Federatsii, 2017,187 p.

10. Chernyshov A. G. Vlast' kak «vechnyi» dvigatel’: Monografiya [Power as a «perpetual» engine: Monograph]. M.: Prospekt, 2017, 40 p.

11. Chulanova O. L. Metodologiya issledovaniya kompetentsii personala organizatsii: Monografiya. [Methodology for the study of the competence of staff organizations: Monograph], M.: INFRA-M, 2015, 120 p. 